\title{
Critical update for the clinical use of L-carnitine analogs in cardiometabolic disorders
}

\author{
This article was published in the following Dove Press journal: \\ Vascular Health and Risk Management \\ 25 March 20II \\ Number of times this article has been viewed
}

\section{Carmen Mingorance \\ Rosalía Rodríguez- \\ Rodríguez \\ María Luisa Justo \\ María Álvarez de \\ Sotomayor \\ María Dolores Herrera}

Department of Pharmacology,

School of Pharmacy,

University of Seville, Seville, Spain
Correspondence: María Dolores Herrera c/ Profesor García González n² 2 ,

Zip code 4I0I2, Seville, Spain

$\mathrm{Tel}+34954559878$

Fax +34954556074

Email mdherrera@us.es
Abstract: Acetyl-L-carnitine (ALC) and propionyl-L-carnitine (PLC) are two naturally occurring carnitine derivates formed by carnitine acetyltransferase. The beneficial cardiovascular effects of ALC and PLC have been extensively evaluated in animals and humans during the last 20 years. For instance, many clinical trials have suggested ALC and PLC as potential strategies in the management of peripheral arterial disease, heart and cerebral ischemia, and congestive heart failure. As a result, several experts have already aimed to revise the clinical evidence supporting the therapeutic use of ALC and PLC. On the basis of their conclusions, our aim was a critical review of the effectiveness of ALC and PLC in the treatment of cardiovascular diseases. Type 2 diabetes mellitus is an independent risk factor for the development of cardiovascular disease. Therefore we also describe recent studies that have addressed the emerging use of ALC and PLC amelioration of the insulin resistant state and its related morbidities.

Keywords: propionyl-L-carnitine, acetyl-L-carnitine, L-carnitine, cardiovascular diseases, insulin resistance

\section{Introduction}

L-carnitine (LC) is a non-protein amino acid, which is synthesized in mammals from the essential amino acids lysine and methionine or obtained from dietary sources. ${ }^{1,2}$ Acetyl-L-carnitine (ALC) and propionyl-L-carnitine (PLC) are two naturally occurring carnitine derivatives the formation of which is catalyzed by carnitine acetyltransferase (CAT), an enzyme present in mitochondria and peroxisomes and highly expressed in liver and heart tissues. ${ }^{3,4}$

LC is an essential cofactor of carnitine palmitoyltransferanse 1 (CPT1), allowing fatty acid transport into mitochondria and the incorporation of long chain fatty acids into the $\beta$-oxidation cycle to obtain acetyl-CoA. LC not only plays an important role in fatty acid metabolism, but also in glucose metabolism through its role in modulating the intramitochondrial acetyl-CoA/CoA ratio and the pyruvate dehydrogenase complex (PDH) (Figure 1). ${ }^{5,6}$

Regulation by LC of the supply of energy is especially important in heart tissue. ${ }^{7}$ Moreover, cardiovascular diseases, such as heart failure and ischemia, are frequently accompanied by decreased myocardial ATP levels leading to lower mechanical work efficiency. ${ }^{8}$ Thus LC and its derivatives have been considered for use in metabolic therapies which may help cardiomyocytes meet their absolute need for ATP, preserve the pulsatile cardiac function, and maintain cell and tissue viability. ${ }^{9-11}$

Another well recognized physiological role of LC is to increase the efflux of acyl and acetyl groups (such as the acyl-carnitines and acetyl-carnitine, respectively) out of cells 


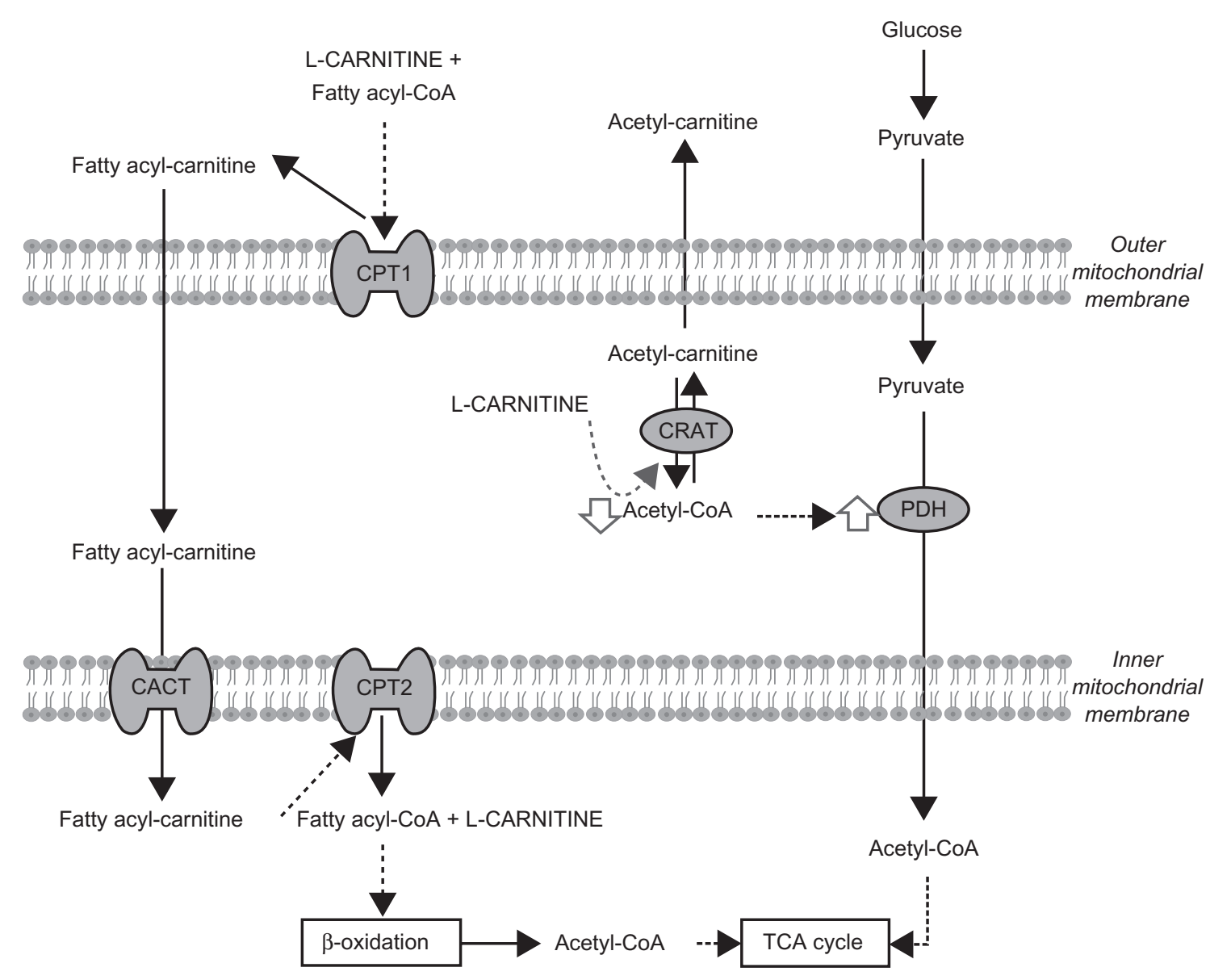

Figure I L-carnitine and energy metabolism.

Abbreviations: CPT, carnitine polmitoyl transferase; CRAT, Acetyl-carnitine transferase; CACT, carnitine-acylcarnitine translocase; TCA, tricarboxylic acid.

into the plasma, reducing the accumulation of the intermediate products of $\beta$-oxidation. ${ }^{12}$ Accumulation of these intermediates has been implicated in the development of insulin resistance in heart and skeletal muscle and of heart failure and ischemia. ${ }^{13-16}$ Accordingly, exogenous administration of PLC and ALC may have beneficial effects in the treatment of insulin resistance and cardiovascular diseases, by restoring tissue carnitine of skeletal muscle and myocardium.

The carnitine esters, ALC and PLC, appear to possess significant strengths over L-carnitine itself. Briefly, ALC, thanks to its chemical structure, may have a preferential effect on the brain tissue. As for PLC, its propionyl moiety may replenish one of the intermediates in the citric acid cycle exerting an anaplerotic effect.

The potential therapeutic effects of PLC and ALC in the treatment of cardiovascular diseases have been evaluated since the mid-1980s, ${ }^{17,18}$ and over the last decade numerous reviews have already attempted to summarize the experimental and clinical evidence supporting these beneficial cardiovascular effects. ${ }^{9,11,19-29}$
On the other hand, type 2 diabetes mellitus (T2DM) is widely accepted to be an independent risk factor for several cardiovascular disorders: coronary heart disease, stroke, peripheral arterial disease, cardiomyopathy, and congestive heart failure. Interestingly, the most recent data concerning the clinical use of ALC and PLC suggest these LC analogs as potential tools in the management of insulin resistance and T2DM.

In this review, we aim to provide a critical appraisal of the effectiveness of ALC and PLC in the treatment of cardiovascular diseases, and to summarize the emerging findings of studies examining the likely effectiveness of PLC and ALC in the improvement of insulin resistance.

\section{Therapeutic effects of L-carnitine analogs on cardiovascular diseases}

The cardiovascular effects of L-carnitine and its analogs have already been extensively reviewed by various experts in this field. For that reason, the main aim of this section is to identify points in common between the different reviews rather than summarizing once again data from the original clinical trials. 


\section{Peripheral arterial disease}

Peripheral arterial disease (PAD) is a clinical manifestation of underlying aorto-iliac and leg atherosclerosis, which is characterized by different degrees of stenosis and obstruction. Intermittent claudication (IC) is the main symptom of PAD and it is defined as cramping leg pain (in the buttocks, thighs, and/or calves) while/after climbing 1 or 2 flights of stairs, or during walking.

The beneficial effects of PLC on PAD, especially in alleviating the IC, have been widely studied, being more relevant than those exerted by LC itself. ${ }^{30}$ In contrast, the effects of ALC on PAD have been poorly evaluated. Some reviews focused on these effects are the main sources considered in the present analysis. ${ }^{26,27,29}$

Intermittent claudication is a symptom that profoundly limits the patient's ability to walk and as a result is associated with reduced exercise performance. Thus the primary goal of claudication therapy is to relieve the symptoms during walking and improve exercise performance and community activities. ${ }^{31}$ In relation to the efficacy of PLC in the treatment of PAD, the authors of these three reviews agreed on highlighting the ability of PLC to improve exercise tolerance in terms of increasing the maximum walking distance (MWD) in patients suffering from IC. This increased MWD has been shown to be independent of the dosage ( $1-3 \mathrm{~g} /$ day), route of administration (intravenous infusion or oral intake), and duration of PLC treatment (short or long term administration) used in the different studies included in the reviews (Table 1)..$^{30,32-41}$

The authors of these reviews emphasized the importance of the clinical trial managed by Brevetti et $\mathrm{al}^{33}$ as the largest study so far, recruiting 485 patients. In this pivotal trial, after 12 months of treatment with $2 \mathrm{~g}$ /day of PLC, patients with an initial MWD $<250 \mathrm{~m}$, and randomly allocated to placebo, increased their MWD by $44 \%$ vs $61 \%$ in the cases receiving the drug $(P<0.055)$. However, patients with mild functional impairment (MWD $>250 \mathrm{~m}$ ) showed no response to PLC. ${ }^{33}$

The reviewers also concluded that PLC seems to be able to improve most measures of quality of life (overall physical activity, pain while walking, and psychological activity) with PLC-treated patients with PAD obtaining better scores than placebo recipients on several different validated questionnaires (namely, the McMaster Health Index Questionnaire [MHIQ], Walking Impairment Questionnaire and the Medical Outcome Study SF-36 Questionnaire). In all the reviews, however, 1 study, focused mainly on assessing the effect of PLC treatment on patient quality of life, was noted as having failed to detect any significant

Table I Main clinical trials on patients with intermittent claudication (IC) showed an increase of the maximal walking distance (MWD) after receiving PLC treatment, regardless of the dose, route of administration or duration used in the different studies

\begin{tabular}{|c|c|c|c|c|c|c|c|c|c|}
\hline & \multirow{2}{*}{$\begin{array}{l}\text { Patients } \\
\text { (n) }\end{array}$} & \multirow{2}{*}{$\begin{array}{l}\text { PLC } \\
\text { dose }\end{array}$} & \multirow{2}{*}{$\begin{array}{l}\text { Duration } \\
\text { (days) }\end{array}$} & \multirow{2}{*}{$\begin{array}{l}\text { Route of } \\
\text { administration }\end{array}$} & \multirow[t]{2}{*}{ Diagnosis } & \multicolumn{2}{|c|}{ MWD increase } & \multirow[t]{2}{*}{$P$ value } & \multirow{2}{*}{$\begin{array}{l}\text { Quality } \\
\text { of life } \\
\text { test }\end{array}$} \\
\hline & & & & & & PLC & Placebo & & \\
\hline $\begin{array}{l}\text { Brevetti } \\
\text { et } \mathrm{al}^{30}\end{array}$ & 33 & $600 \mathrm{mg} /$ day & 4 days & i.v & PAD and IC (Fontaine II) & 20 & NR & $P<0.0 I^{a}$ & NR \\
\hline $\begin{array}{l}\text { Coto } \\
\text { et } \mathrm{al}^{32}\end{array}$ & 282 & 2 g/day & 180 & Oral & PAD and IC & 93 & 35 & NR & NR \\
\hline $\begin{array}{l}\text { Brevetti } \\
\text { et } \mathrm{al}^{33,34}\end{array}$ & 214 & $\begin{array}{l}500 \mathrm{mg}- \\
3 \mathrm{~g} / \mathrm{day}\end{array}$ & 182 & Oral & $\begin{array}{l}\text { IC }(30<M W D<400) \\
\text { Severe IC }(30<M W D<250)\end{array}$ & $\begin{array}{l}157 \\
124\end{array}$ & |39,57| & $\begin{array}{l}0.026^{b} \\
0.009^{b}\end{array}$ & $\begin{array}{l}\sqrt{ } \\
\sqrt{ }\end{array}$ \\
\hline $\begin{array}{l}\text { Brevetti } \\
\text { et } \mathrm{al}^{35}\end{array}$ & 485 & 2 g/day & 365 & Oral & $\begin{array}{l}\mathrm{IC}(50<\mathrm{MWD}<400) \\
\text { Severe IC }(30<\mathrm{MWD}<250)\end{array}$ & $\begin{array}{l}54 \% \\
87 \%\end{array}$ & $\begin{array}{l}48 \% \\
46 \%\end{array}$ & $\begin{array}{l}\mathrm{NS}^{\mathrm{b}} \\
P<0.0 \mathrm{I}^{\mathrm{b}}\end{array}$ & $\begin{array}{l}X \\
\sqrt{ }\end{array}$ \\
\hline $\begin{array}{l}\text { Dal Lago } \\
\text { et } \mathrm{al}^{36}\end{array}$ & 19 & $3 \mathrm{~g} /$ day & 90 & Oral & $\begin{array}{l}\text { Obliterative PAD } \\
\text { (Fontaine II) }\end{array}$ & 143.3 & 17.7 & $P<0.05^{b}$ & NR \\
\hline Hiatt $^{37}$ & 155 & 2 g/day & 180 & Oral & PAD and IC & $161 \mathrm{seg}$ & 75 seg & $P<0.0001^{b}$ & $\sqrt{ }$ \\
\hline $\begin{array}{l}\text { Barker } \\
\text { et } \mathrm{al}^{38}\end{array}$ & 7 & 2 g/day & 28 & Oral & PAD and IC & $80 \mathrm{seg}$ & $0 \mathrm{seg}$ & NS & NR \\
\hline $\begin{array}{l}\text { Ragozzino } \\
\text { et } \mathrm{al}^{39}\end{array}$ & 24 & I, 2 g/day & 10 & i.v & $\begin{array}{l}\text { Diabetic angiopathy } \\
\text { (Fontaine Ilb) }\end{array}$ & $30 \%$ & NR & $P<0.05^{\mathrm{a}}$ & NR \\
\hline $\begin{array}{l}\text { Andreozzi } \\
\text { et } \mathrm{al}^{40}\end{array}$ & 42 & $600 \mathrm{mg} /$ day & 42 & i.v & $\begin{array}{l}\text { Moderate IC (MWD < 200) } \\
\text { Severe IC }(M W D<100)\end{array}$ & $\begin{array}{l}\cong 78.75 \\
\cong 107.37\end{array}$ & $\begin{array}{l}\cong 60.09 \\
\cong 76.64\end{array}$ & $\begin{array}{l}P<0.006^{\mathrm{b}} \\
P<0.0003^{\mathrm{b}}\end{array}$ & NR \\
\hline $\begin{array}{l}\text { Allegra } \\
\text { et } \mathrm{al}^{41}\end{array}$ & 26 & 900 mg/day & 33 & i.v & $\begin{array}{l}\text { Angiopathy } \\
\text { (Fontaine lla and b) }\end{array}$ & 157 & NR & $P<0.00 \mathrm{I}^{\mathrm{a}}$ & NR \\
\hline
\end{tabular}

Notes: aPlacebo period in the same group; 'Placebo group.

Abbreviations: NR, not registered; NS, not statistically significant. 
improvements in MHIQ scores in patients with mild claudication treated with PLC. ${ }^{33}$

One of the symptoms leading to the development of IC is a decreased blood flow in patients with PAD. Wiseman and Brogden concluded that PLC had no direct vasoactive effects in patients with IC. ${ }^{29}$ However, other scholars mentioned the capacity of PLC to improve endothelial function, ${ }^{26,42}$ and some years later, Andreozzi gathered clinical evidence demonstrating the beneficial effects of PLC treatment on the vasculature of patients with PAD. ${ }^{27}$ More precisely, this recent review concluded that PLC has an ability to enhance flow mediated dilatation (FMD) in the brachial artery, ${ }^{43}$ even when impaired post-exercise. ${ }^{44}$ This vasoactive effect of PLC may help to prevent the occurrence of ischemic events in patients with PAD.

Eventually, PAD progresses from IC to ischemic ulcers or gangrene. In this regard, it has been mentioned in some reviews; ${ }^{27,29}$ many scholars have noted the importance of early studies demonstrating that PLC improved healing of ulcerative trophic lesions in patients with severe chronic obstructive arterial disease. ${ }^{29,45,46}$

Because patients with claudication are physically impaired, the treatment goals are to relieve symptoms, and improve exercise performance and daily quality of life. ${ }^{31}$ Consequently, PLC should be considered not only as a potential or emerging candidate, but as a therapeutic approach that is likely to be effective for the treatment of IC in patients with PAD.

Its effectiveness may be enhanced by combining PLC with other strategies, such as exercise training, pulsed muscular compression therapy, or pharmacological treatment with PGE-1. ${ }^{47,48}$ Accordingly, the latest update of the Inter-Society Consensus for the Management of PAD guidelines (TASC II) included the use of PLC in combination with physical training to improve the symptoms associated with PAD. ${ }^{31}$ We should also note that, surprisingly, it has recently been reported that the long-term administration of PLC to patients with IC did not result in a statistically significant improvement in peak treadmill performance or quality of life compared with exercise alone. ${ }^{49}$

\section{Ischemic heart disease}

A low carnitine concentration in the heart was observed in patients who died of myocardial infarction, ${ }^{50}$ so that PLC and ALC may be beneficial in the treatment or in the prevention of damage to the heart after an ischemic insult. In relation to this, the usefulness of $\mathrm{LC}$ derivatives in the pharmacological management of the ischemic heart has been strongly supported by research findings in the case of PLC, whereas there is only weak evidence of the effects of ALC on the hypoxic myocardium from isolated rat heart models. ${ }^{51-54}$

The role of PLC in the human pharmacology of the ischemic heart has already been revised by Arsenian, ${ }^{19}$ and Lango et al. ${ }^{24}$ The former and more recent remarked on 2 studies in which PLC demonstrated its beneficial effects in a group of 31 patients with left coronary artery disease treated with a single dose of $15 \mathrm{mg} / \mathrm{kg}$ of PLC and in a group of 18 men with stable exertional angina treated with PLC $1.5 \mathrm{mg}$ /day for 30 days, mainly in terms of a reduction in the ST segment depression that is normally observed after an ischemic episode. ${ }^{19,55,56}$ This reviewer concluded that the function of LC and PLC in ischemic heart disease, though promising, was largely speculative, however. Further, Lango et al in their revision only cited a study where PLC used in doses of $15 \mathrm{mg} / \mathrm{kg}$ caused a slight decrease in peripheral resistance in patients with stable coronary disease. ${ }^{24,57}$

Additional to that found in these reviews, a doubleblind, placebo-controlled study carried out with PLC on patients with stable angina showed a reduction of ST segment depression, together with increased total work capacity and prolonged exercise duration and time to ischemic threshold. ${ }^{58}$ However, the anti-ischemic effects of PLC were less pronounced than those produced by the calcium antagonist diltiazem, PLC being able to reduce ST depression at maximal exercise, but not to increase the time to onset of angina. ${ }^{59}$

In accordance with the previous reviewers, we should conclude that PLC has interesting protective effects against myocardial ischemia, but that its role in the treatment of this condition is not well established.

Nevertheless, it must be pointed out that intravenous PLC administration prior to coronary artery bypass grafting significantly improved early postoperative recovery in diabetic patients by increasing the cardiac index and reducing pulmonary artery pressure, ${ }^{60}$ suggesting that PLC may be more effective in preventing ischemic injury, than in treatment of the consequences after an ischemic episode has occurred.

\section{Cerebral ischemia}

In contrast to the case of the ischemic heart, the therapeutic effect of ALC on cerebral ischemia has been thoroughly investigated, whereas we are aware of only 1 study of PLC administration, in a rat model of forebrain ischemia. ${ }^{61}$ 
Nevertheless, the positive results observed in this study open up new perspectives for the use of PLC in the treatment of neurodegenerative diseases associated with, or secondary to, myocardial ischemia-reperfusion injury and chronic circulatory failure.

Most of the studies focused on the evaluation of the effects of ALC treatment in cerebral ischemic injury did not describe clinical but rather experimental data, which have been review by different experts. ${ }^{22,62,63}$ These reviews noted that ALC has been reported to improve neurological outcome, ${ }^{22}$ prevent free radical-mediated protein oxidation, ${ }^{64}$ normalize levels of brain energy metabolites, and decrease lactic acid concentration during early post-ischemia reperfusion. ${ }^{65}$ More recently, these findings have been confirmed by Jalal et al who found that pretreatment with ALC (400 mg/kg/day for 5 days) significantly reduced infarct size in focal cerebral ischemia induced using 4 models of middle cerebral artery occlusion in rats. ${ }^{66}$

To date, however, there are insufficient clinical data supporting the use of ALC in damage prevention or treatment of patients with cerebral ischemia. For instance, in a very recent article focused on $\mathrm{ALC},{ }^{11}$ only 1 study performed in humans with brain ischemia was mentioned and that had been published back in $1990 .{ }^{67}$ In this study, they investigated the effects of ALC on regional cerebral blood flow in 10 male patients with brain ischemia and observed beneficial effects in 8 out of 10 patients 1 hour after IV administration of $1500 \mathrm{mg}$ of ALC. ${ }^{67}$

Considering the great extent of experimental data in the literature that strongly support the beneficial effects of ALC in cerebral ischemia, we note that there is a pressing need for well planned clinical trials considering ALC as a potential pharmacological instrument in patients with brain ischemia.

\section{Congestive heart failure}

Since PLC and ALC may improve the impaired metabolism of heart muscle, these LC analogs may provide considerable benefits as adjuncts to standard therapy in congestive heart failure (CHF).

Similar to the effects observed in the cardiovascular conditions described above, the effectiveness of PLC in the clinical management of CHF has been more widely discussed than the use of ALC. Indeed, the effects of ALC on heart failure are only indirectly suggested by 2 studies, one performed in patients with heart failure secondary to circulatory shock and the other in patients with coronary artery disease, which is one of the main causes for development of $\mathrm{CHF}^{68,69}$ In the former,
115 patients with circulatory and septic shock received ALC infusion for 12 hours with a previous single bolus intravenously. The results showed a good response to the drug in terms of blood oxygenation during the course of sepsis and heart failure. ${ }^{68}$ In the latter, 36 subjects with stable coronary artery disease received $500 \mathrm{mg}$ oral ALC and $200 \mathrm{mg}$ oral $\alpha$-lipoic acid twice daily and their effect on vascular function and blood pressure were assessed. The trial consisted of two 8-week treatment periods separated by a 4 -week washout period, after which subjects were crossed over to the other group. The combined treatment increased brachial artery diameter by $2 \%$ to $3 \%$ and decreased systolic blood pressure by an average of $9 \mathrm{~mm} \mathrm{Hg}$, compared with placebo. ${ }^{69}$

The ability of PLC treatment to improve CHF was reviewed by Ferrari et al in 1997 and 2004. ${ }^{9,70}$ The authors concluded that both acute and chronic administration of PLC improved exercise capacity in patients with moderate and severe CHF (New York Heart Association classes II-IV), occurring in the absence of major hemodynamic and neuroendocrine changes, but were associated with an improved skeletal muscle metabolism, and were likely to decrease levels of the tumor necrosis factor- $\alpha$, a proinflammatory soluble receptor that is elevated in $\mathrm{CHF}^{71,72}$

Comparing the two reviews, only slight progress seems to have been made over the 7 years that elapsed between them in the clinical evidence supporting the use of PLC in CHF. Moreover, Ferrari et al also remarked on the importance of a multicenter and international study in which only a slight non-significant difference on exercise test duration was detected. ${ }^{73}$ That study found that only in a subgroup of patients, with an ejection fraction of $30 \%$ to $40 \%$ and with relatively well preserved myocardial function, were results in the exercise duration test enhanced significantly after PLC treatment.

Consequently, we can conclude that the clinical effectiveness of PLC in the treatment of CHF is not well established.

\section{L-carnitine analogs in diabetes mellitus in clinical practice}

Patients with type 1 or type 2 diabetes are at high risk of various cardiovascular disorders: coronary heart disease, stroke, peripheral arterial disease, cardiomyopathy, and congestive heart failure. Indeed, cardiovascular complications have been identified as the leading causes of diabetes-related morbidity and mortality. ${ }^{74}$

Accumulation of fatty acids and lipid metabolites (such as long chain acyl CoA, diacylglycerol, triacylglycerol, and/or ceramide) has been reported to alter the insulin action 
pathway and consequently can be considered as a likely mechanism for the development of insulin resistance in heart and skeletal muscles, probably through the activation of proinflammatory pathways. ${ }^{75,76}$ LC plays an important role in the efflux of these intermediates from the cell and may also be decreasing their accumulation by inhibiting the transport of long chain free fatty acids into the cell. In fact, a connection between LC and CPT1 inhibition through an increase of the malonyl-CoA levels has been suggested. ${ }^{77}$ For these reasons, LC and its derivatives may act in various ways to improve insulin resistance.

LC improved insulin-mediated glucose disposal has been demonstrated in both healthy subjects and in patients with T2DM. ${ }^{78}$ Since either LC or its derivatives play an important role in fatty acid and glucose oxidation, and both have been found to be altered in T2DM, it can reasonably be hypothesized that PLC and ALC would have beneficial effects in T2DM.

For instance, the first report showing the anti-diabetic effect of ALC was published by Giancaterini et al 10 years ago. ${ }^{79}$ On different days, $18 \mathrm{~T} 2 \mathrm{DM}$ patients received both a primed-constant infusion of ALC $(5 \mathrm{mg} / \mathrm{kg}$ body weight priming bolus and either $0.025,0.1$, or $1.0 \mathrm{mg} / \mathrm{kg}$ body weight/min constant infusion) and a comparable placebo formulation. Tissue glucose uptake was significantly increased by the administration of ALC, in a dose-dependent manner, and was related to increased glucose storage rather than increased glucose oxidation. ${ }^{79}$

More recently, new data continue to point to the likely effectiveness of ALC administration in the clinical management of T2DM. Bloomer et al conducted a double-blind clinical trial in which pre-diabetic men and women (with fasting blood glucose: 100-125 $\mathrm{mg} / \mathrm{dL}$ ) were randomly assigned either $3 \mathrm{~g}$ /day of ALC or placebo for 8 weeks, resulting in slight improvements in fasting glucose, $\mathrm{HbA}_{1 \mathrm{c}}$ and HOMA-IR after ALC treatment. ${ }^{80}$ Further, when ALC was administered chronically for 24 weeks to 36 non-diabetic patients ( $2 \mathrm{~g}$ /day) with insulin resistance and hypertension at increased risk of cardiovascular disease, the treatment resulted in an increased glucose disposal rate and improved glucose tolerance in PLC-treated patients. Additionally, higher values of glucose disposal rate were accompanied by higher decreases of systolic blood pressure. ${ }^{81}$ The results of this pilot study may provide the basis on which to set up randomized, double-blind clinical trials to formally test the effects of ALC compared with placebo on blood pressure and metabolic profile in T2DM and hypertensive patients.
Finally, it should be mentioned that the effects of PLC on insulin resistance have been reported for the first time following a recent study performed in an animal model of obesity and insulin resistance, the fatty Zucker rat. ${ }^{82} \mathrm{Chronic}$ administration of oral PLC decreased the body-weight gain, food intake, adiposity, insulin serum concentration, HOMA-IR index, and TAG liver content, demonstrating the considerable improvement of the insulin resistance that had occurred in animals receiving PLC. ${ }^{82}$

\section{Conclusion}

Although several clinical trials suggest PLC and ALC as potential pharmacological tools targeting cardiovascular pathologies (namely PAD, brain and heart ischemia, and $\mathrm{CHF}$ ), only the effectiveness of PLC in the management of the IC in the PAD can be remarked. In relation to this, PLC seems to be more effective when it is combined with other strategies, such as exercise training, pulsed muscular compressions or other pharmacological strategies, suggesting a special role of PLC as a coadjuvant tool in the therapy of IC. In contrast, most of the recent studies evaluated the efficacy of ALC in the amelioration of the insulin resistance state. Nevertheless, well designed and larger clinical trials are still necessary to establish more strongly the beneficial effects of the LC analogs in T2DM.

\section{Disclosure}

The authors declare no conflicts of interest.

\section{References}

1. Rebouche CJ. Carnitine function and requirements during the life cycle. FASEB J. 1992;6(15):3379-3386.

2. Demarquoy J, Georges B, Rigault C, Royer MC. Radioisotopic determination of L-carnitine content in foods commonly eaten in Western countries. Food Chem. 2004;86:137-142.

3. Zammit VA. Carnitine acyltransferases: functional significance of subcellular distribution and membrane topology. Prog Lipid Res. 1999; 38(3):199-224.

4. Ferri L, Valente M, Ursini F, et al. Acetyl-carnitine formation and pyruvate oxidation in mitochondria from different rat tissues. Bull Mol Biol Med. 1981;6(1-2):16-23.

5. Lysiak W, Lilly K, DiLisa F, Toth PP, Bieber LL. Quantitation of the effect of L-carnitine on the levels of acid-soluble short-chain acyl-CoA and CoASH in rat heart and liver mitochondria. J Biol Chem. 1988; 263(3):1151-1156.

6. Broderick TL, Quinney HA, Lopaschuk GD. Carnitine stimulation of glucose oxidation in the fatty acid perfused isolated working rat heart. J Biol Chem. 1992;267(6):3758-3763.

7. Broderick TL, Panagakis G, DiDomenico D, et al. L-carnitine improvement of cardiac function is associated with stimulation in glucose but not fatty acid metabolism in carnitine-deficient hearts. Cardiovasc Res. 1995;30(5):815-820.

8. Abozguia K, Shivu GN, Ahmed I, Phan TT, Frenneaux MP. The heart metabolism: pathophysiological aspects in ischaemia and heart failure. Curr Pharm Des. 2009;15(8):827-835. 
9. Ferrari R, Merli E, Cicchitelli G, Mele D, Fucili A, Ceconi C. Therapeutic effects of L-carnitine and propionyl-L-carnitine on cardiovascular diseases: a review. Ann N Y Acad Sci. 2004;1033:79-91.

10. Revenco D, Morgan JP. Metabolic modulation and cellular therapy of cardiac dysfunction and failure. J Cell Mol Med. 2009;13(5):811-825.

11. Anon. Acetyl-L-carnitine. Monograph. Altern Med Rev. 2010;15(1): 76-83.

12. Chapela SP, Kriguer N, Fernández EH, Stella CA. Involvement of L-carnitine in cellular metabolism: beyond Acyl-CoA transport. Mini Rev Med Chem. 2009;9(13):1518-1526.

13. Zhang L, Keung W, Samokhvalov V, Wang W, Lopaschuk GD. Role of fatty acid uptake and fatty acid beta-oxidation in mediating insulin resistance in heart and skeletal muscle. Biochim Biophys Acta. 2010; 1801(1):1-22.

14. Samuel VT, Petersen KF, Shulman GI. Lipid-induced insulin resistance: unravelling the mechanism. Lancet. 2010;375(9733):2267-2277.

15. Chess DJ, Stanley WC. Role of diet and fuel overabundance in the development and progression of heart failure. Cardiovasc Res. 2008; 79(2):269-278.

16. Van der Vusse GJ, Prinzen FW, van Bilsen M, Engels W, Reneman RS. Accumulation of lipids and lipid-intermediates in the heart during ischaemia. Basic Res Cardiol. 1987;82(Suppl 1):157-167.

17. Paulson DJ, Traxler J, Schmidt M, et al. Protection of the ischemic myocardium by L-propionylcarnitine: effects on the recovery of cardiac output after ischaemia and reperfusion, carnitine transport and fatty acid oxidation. Cardiovasc Res. 1986;20:536-541.

18. Paulson DJ, Schmidt MJ, Romens J, Shug AL. Metabolic and physiologic differences between zeroflow and low-flow myocardial ischemia: effects of L-acetylcarnitine. Basic Res Cardo. 1984;79(5):551-561.

19. Arsenian MA. Carnitine and its derivatives in cardiovascular disease Prog Cardiovasc Dis. 1997;40(3):265-286.

20. Ferrari R, De Giuli F. The propionyl-L-carnitine hypothesis: an alternative approach to treating heart failure. J Card Fail. 1997;3(3):217-224.

21. Retter AS. Carnitine and its role in cardiovascular disease. Heart Dis. 1999;1(2):108-113.

22. Calvani M, Arrigoni-Martelli E. Attenuation by acetyl-L-carnitine of neurological damage and biochemical derangement following brain ischemia and reperfusion. Int J Tissue React. 1999;21(1):1-6.

23. Calvani M, Reda E, Arrigoni-Martelli E. Regulation by carnitine of myocardial fatty acid and carbohydrate metabolism under normal and pathological conditions. Basic Res Cardiol. 2000;95(2):75-83.

24. Lango R, Smolenski RT, Narkiewicz M, Suchorzewska J, LysiakSzydlowska W. Influence of L-carnitine and its derivatives on myocardial metabolism and function in ischemic heart disease and during cardiopulmonary bypass. Cardiovasc Res. 2001;51(1):21-29.

25. Hagen TM, Moreau R, Suh JH, Visioli F. Mitochondrial decay in the aging rat heart: evidence for improvement by dietary supplementation with acetyl-L-carnitine and/or lipoic acid. Ann N Y Acad Sci. 2002; 959:491-507.

26. Hiatt WR. Carnitine and peripheral arterial disease. Ann NY Acad Sci. 2004;1033:92-98.

27. Andreozzi GM. Propionyl 1-carnitine: intermittent claudication and peripheral arterial disease. Expert Opin Pharmacother. 2009;10(16) 2697-2707.

28. Rosca MG, Lemieux H, Hoppel CL. Mitochondria in the elderly: is acetylcarnitine a rejuvenator? Adv Drug Deliv Rev. 2009;61(14): 1332-1342.

29. Wiseman LR, Brogden RN. Propionyl-L-carnitine. Drugs Aging. 1998; 12(3):243-248.

30. Brevetti G, Perna S, Sabba C, et al. Superiority of L-propionylcarnitine vs L-carnitine in improving walking capacity in patients with peripheral vascular disease: an acute, intravenous, double-blind, cross-over study. Eur Heart J. 1992;13(2):251-255.

31. Norgren L, Hiatt WR, Dormandy JA, et al. Inter-Society Consensus for the Management of Peripheral Arterial Disease (TASC II). Eur J Vasc Endovasc Surg. 2007;33(Suppl 1):S1-S75.
32. Coto V, D'Alessandro L, Grattarola G, et al. Evaluation of the therapeutic efficacy and tolerability of levocarnitine propionyl in the treatment of chronic obstructive arteriopathies of the lower extremities: a multicentre controlled study vs placebo. Drugs Exp Clin Res. 1992; 18(1):29-36.

33. Brevetti G, Perna S, Sabbá C, Martone VD, Condorelli M. PropionylL-carnitine in intermittent claudication: double-blind, placebocontrolled, dose titration, multicenter study. J Am Coll Cardiol. 1995; 26(6):1411-1416.

34. Brevetti G, Perna S, Sabba C, Martone VD, Di Iorio A, Barletta G. Effect of propionyl-L-carnitine on quality of life in intermittent claudication. Am J Cardiol. 1997;79(6):777-780.

35. Brevetti G, Diehm C, Lambert D. European multicenter study on propionyl-L-carnitine in intermittent claudication. $\mathrm{J} \mathrm{Am} \mathrm{Coll} \mathrm{Cardiol.}$ 1999;34(5):1618-1624.

36. Dal Lago A, De Martini D, Flore R, et al. Effects of propionyl-Lcarnitine on peripheral arterial obliterative disease of the lower limbs: a double-blind clinical trial. Drugs Exp Clin Res. 1999;25(1):29-36.

37. Hiatt WR. New treatment options in intermittent claudication: the US experience. Int J Clin Pract Suppl. 2001;(119):20-27.

38. Barker GA, Green S, Askew CD, Green AA, Walker PJ. Effect of propionyl-L-carnitine on exercise performance in peripheral arterial disease. Med Sci Sports Exerc. 2001;33(9):1415-1422.

39. Ragozzino G, Mattera E, Madrid E, et al. Effects of propionyl-carnitine in patients with type 2 diabetes and peripheral vascular disease: results of a pilot trial. Drugs R D. 2004;5(4):185-190.

40. Andreozzi GM, Leone A, Laudani R, Martin R, Deinit G, Cataldi V. Levo-propionyl-carnitine improves the effectiveness of supervised physical training on the absolute claudication distance in patients with intermittent claudication. Angiology. 2008;59(1):84-89.

41. Allegra C, Antignani PL, Schachter I, Koverech A, Messano M, Virmani A. Propionyl-L-carnitine in Leriche-Fontaine stage II peripheral arterial obstructive disease. Ann Vasc Surg. 2008;22(4): $552-558$.

42. Cipolla MJ, Nicoloff A, Rebello T, Amato A, Porter JM. Propionyl-Lcarnitine dilates human subcutaneous arteries through an endotheliumdependent mechanism. J Vasc Surg. 1999;29(6):1097-1103.

43. Loffredo L, Marcoccia A, Pignatelli P, et al. Oxidative-stress-mediated arterial dysfunction in patients with peripheral arterial disease. Eur Heart J. 2007;28(5):608-612.

44. Silvestro A, Schiano V, Bucur R, et al. Effect of propionylcarnitine on changes in endothelial function and plasma levels of adhesion molecules induced by acute exercise in patients with intermittent claudication. Angiology. 2006;57(2):145-154.

45. Pola P, Flore R, Serricchio M, et al. New carnitine derivatives for the therapy of cutaneous ulcers in vasculopathies. Drugs Exp Clin Res. 1991;17(5):277-282.

46. Persico G, Amato B, Aprea G, et al. The early effects of intravenous L-propionyl carnitine on ulcerative trophic lesions of the lower limbs in arteriopathic patients: a controlled randomized study. Drugs Exp Clin Res. 1995;21(5):187-198.

47. Riccioni C, Sarcinella R, Palermo G, et al. Evaluation of the efficacy of propionyl-L-carnitine versus pulsed muscular compressions in diabetic and non-diabetic patients affected by obliterating arteriopathy Leriche stage II. Int Angiol. 2008;27(3):253-259.

48. Milio G, Novo G, Genova C, Luigi Almasio P, Novo S, Pinto A. Pharmacological treatment of patients with chronic critical limb ischemia: L-propionyl-carnitine enhances the short-term effects of PGE-1. Cardiovasc Drugs Ther. 2009;23(4):301-306.

49. Hiatt WR, Creager MA, Amato A, Brass EP. Effect of PropionylL-carnitine on a Background of Monitored Exercise in Patients with Claudication secondary to Peripheral Artery Disease. J Cardiopulm Rehabil Prev. 2010. DOI: 10.1097/HCR.0b013e3181f1fd65.

50. Spagnoli LG, Corsi M, Villaschi S, Palmieri G, Maccari F. Myocardial carnitine deficiency in acute myocardial infarction. Lancet. 1982;1(8286): 1419-1420. 
51. Dhalla NS, Kolár F, Shah KR, Ferrari R. Effects of some L-carnitine derivatives on heart membrane ATPases. Cardiovasc Drugs Ther. 1991; 5(Suppl 1):25-30

52. Löster H, Keller T, Grommisch J, Gründer W. Effects of L-carnitine and its acetyl and propionyl esters on ATP and PCr levels of isolated rat hearts perfused without fatty acids and investigated by means of 31PNMR spectroscopy. Mol Cell Biochem. 1999;200(1-2):93-102.

53. Lesnefsky EJ, He D, Moghaddas S, Hoppel CL. Reversal of mitochondrial defects before ischemia protects the aged heart. FASEB J. 2006; 20(9):1543-1545.

54. Cui J, Das DK, Bertelli A, Tosaki A. Effects of L-carnitine and its derivatives on postischemic cardiac function, ventricular fibrillation and necrotic and apoptotic cardiomyocyte death in isolated rat hearts. Mol Cell Biochem. 2003;254(1-2):227-234.

55. Bartels GL, Remme WJ, Pillay M, Schönfeld DH, Kruijssen DA. Effects of L-propionylcarnitine on ischemia-induced myocardial dysfunction in men with angina pectoris. Am J Cardiol. 1994;74(2):125-130.

56. Cherchi A, Lai C, Onnis E, et al. Propionyl carnitine in stable effort angina. Cardiovasc Drugs Ther. 1990;4(2):481-486.

57. Chiddo A, Gaglione A, Musci S, et al. Hemodynamic study of intravenous propionyl-L-carnitine in patients with ischemic heart disease and normal left ventricular function. Cardiovasc Drugs Ther. 1991; 5(Suppl 1):107-111

58. Lagioia R, Scrutinio D, Mangini SG, et al. Propionyl-L-carnitine: a new compound in the metabolic approach to the treatment of effort angina. Int J Cardiol. 1992;34(2):167-172.

59. Bartels GL, Remme WJ, Holwerda KJ, Kruijssen DA. Anti-ischaemic efficacy of L-propionylcarnitine - a promising novel metabolic approach to ischaemia? Eur Heart J. 1996;17(3):414-420.

60. Lango R, Smoleński RT, Rogowski J, et al. Propionyl-L-carnitine improves hemodynamics and metabolic markers of cardiac perfusion during coronary surgery in diabetic patients. Cardiovasc Drugs Ther. 2005;19(4)267-275.

61. Al-Majed AA, Sayed-Ahmed MM, Al-Omar FA, Al-Yahya AA, Aleisa AM, Al-Shabanah OA. Carnitine esters prevent oxidative stress damage and energy depletion following transient forebrain ischaemia in the rat hippocampus. Clin Exp Pharmacol Physiol. 2006;33(8):725-733.

62. Martin E, Rosenthal RE, Fiskum G. Pyruvate dehydrogenase complex: metabolic link to ischemic brain injury and target of oxidative stress. J Neurosci Res. 2005;79(1-2):240-247.

63. Zanelli SA, Solenski NJ, Rosenthal RE, Fiskum G. Mechanisms of ischemic neuroprotection by acetyl-L-carnitine. Ann NY Acad Sci. 2005; 1053:153-161.

64. Rosenthal RE, WiUiams R, Bogaert YE, et al. Prevention of postischemic canine neurological injury through potentiation of brain energy metabolism by acetyl-Lcarnitine. Stroke 1992;23:1312-1317.

65. Aureli T, Miccheh A, Di Coceo ME, et al. Effect of acetyl-L-carnitine on recovery of brain phosphorus metabolites and lactic acid level during reperfusion after cerebral ischemia in the rat - study by $13 \mathrm{P}$ - and $1 \mathrm{H}-$ NMR spectroscopy. Brain Res 1994;643:92-99.

66. Jalal FY, Böhlke M, Maher TJ. Acetyl-L-carnitine reduces the infarct size and striatal glutamate outflow following focal cerebral ischemia in rats. Ann NY Acad Sci. 2010;1199:95-104.
67. Rosadini G, Marenco S, Nobili F, et al. Acute effects of acetyl-L-carnitine on regional cerebral blood flow in patients with brain ischaemia. Int $J$ Clin Pharmacol Res. 1990;10:123-128.

68. McMackin CJ, Widlansky ME, Hamburg NM, et al. Effect of combined treatment with alpha-Lipoic acid and acetyl-L-carnitine on vascular function and blood pressure in patients with coronary artery disease. J Clin Hypertens (Greenwich). 2007;9(4):249-255.

69. Gasparetto A, Corbucci GG, De Blasi RA, et al. Influence of acetyl-Lcarnitine infusion on haemodynamic parameters and survival of circulatory-shock patients. Int J Clin Pharmacol Res. 1991;11(2):83-92.

70. Ferrari R, De Giuli F. The propionyl-L-carnitine hypothesis: an alternative approach to treating heart failure. J Card Fail. 1997;3(3):217-224.

71. Ferrari R, Bachetti T, Confortini R, et al. Tumor necrosis factor soluble receptors in patients with various degrees of congestive heart failure. Circulation. 1995;92(6):1479-1486.

72. Ferrari R. Tumor necrosis factor in CHF: a double facet cytokine. Cardiovasc Res.1998;37(3):554-559.

73. The investigators of the study on propionyl-L-carnitine in chronic heart failure. Study on propionyl-L-carnitine in chronic heart failure. Eur Heart J. 1999;20(1):70-76.

74. Anon. Diabetes mellitus: a major risk factor for cardiovascular disease. A joint editorial statement by the American Diabetes Association; The National Heart, Lung, and Blood Institute; The Juvenile Diabetes Foundation International; The National Institute of Diabetes and Digestive and Kidney Diseases; and The American Heart Association. Circulation. 1999;100(10):1132-1133.

75. Zhang L, Keung W, Samokhvalov V, Wang W, Lopaschuk GD. Role of fatty acid uptake and fatty acid beta-oxidation in mediating insulin resistance in heart and skeletal muscle. Biochim Biophys Acta. 2010; 1801(1):1-22.

76. Adams SH, Hoppel CL, Lok KH, et al. Plasma acylcarnitine profiles suggest incomplete long-chain fatty acid beta-oxidation and altered tricarboxylic acid cycle activity in type 2 diabetic African-American women. J Nutr. 2009;139(6):1073-1081.

77. Ramsay RR, Zammit VA. Carnitine acyltransferases and their influence on CoA pools in health and disease. Mol Aspects Med. 2004;25(5-6): 475-493.

78. Mingrone G. Carnitine in type 2 diabetes. Ann N Y Acad Sci. 2004; 1033:99-107.

79. Giancaterini A, De Gaetano A, Mingrone G, et al. Acetyl-L-carnitine infusion increases glucose disposal in type 2 diabetic patients. Metabolism. 2000;49(6):704-708.

80. Bloomer RJ, Fisher-Wellman KH, Tucker PS. Effect of oral acetyl L-carnitine arginate on resting and postprandial blood biomarkers in pre-diabetics. Nutr Metab (Lond). 2009;6:25.

81. Ruggenenti P, Cattaneo D, Loriga G, et al. Ameliorating hypertension and insulin resistance in subjects at increased cardiovascular risk: effects of acetyl-L-carnitine therapy. Hypertension. 2009;54(3):567-574.

82. Mingorance C, Gonzalez del Pozo M, Dolores Herrera M, Alvarez de Sotomayor M. Oral supplementation of propionyl-1-carnitine reduces body weight and hyperinsulinaemia in obese Zucker rats. $\mathrm{Br} J$ Nutr. 2009;102(8):1145-1153.
Vascular Health and Risk Management

\section{Publish your work in this journal}

Vascular Health and Risk Management is an international, peer-reviewed journal of therapeutics and risk management, focusing on concise rapid reporting of clinical studies on the processes involved in the maintenance of vascular health; the monitoring, prevention and treatment of vascular disease and its sequelae; and the involvement of

\section{Dovepress}

metabolic disorders, particularly diabetes. This journal is indexed on PubMed Central and MedLine. The manuscript management system is completely online and includes a very quick and fair peer-review system, which is all easy to use. Visit http://www.dovepress.com/ testimonials.php to read real quotes from published authors. 